Original Article

\title{
IDENTIFICATION AND ASSESSMENT OF PREDIABETES-A RURAL INDIAN STUDY (A CORRELATIVE STUDY BETWEEN QUESTIONNAIRE AND BIOCHEMICAL ANALYSIS)
}

\author{
VENKATESAN S. ${ }^{*}$, SUSILA S. ${ }^{2}$, SUTHANTHIRAN S. ${ }^{3}$, MADHUSUDHAN S. ${ }^{4}$, PAARI N. ${ }^{5}$ \\ 1,2,3,4Department of Pharmacy, Annamalai University, Chidambaram, 50partment of Medicine, Rajah Muthaiah Medical College Hospital, \\ Chidambaram, Tamil Nadu, India 608002 \\ Email: venky366463@gmil.com
}

Received: 06 May 2020, Revised and Accepted: 15 Jun 2020

ABSTRACT

Objective: To identify and prevent the vulnerable prediabetic population becoming diabetic patients in the future using the Indian Diabetic Risk Score (IDRS) and to evaluate the performance of the IDRS questionnaire for detecting prediabetes and predicting the risk of Type 2 Diabetes Mellitus in Chidambaram rural Indian population.

Methods: A cross-sectional descriptive study was carried out among patients attending a master health check-up of RMMCH hospital located at Chidambaram. The IDRS was calculated by using four simple measures of age, family history of diabetes, physical activity, and waist measurement. The relevant blood test, like Fasting plasma glucose (FBS), Glycated hemoglobin (HbA1C) test, were observed for identifying prediabetes. Subjects were classified as Normoglycemic, prediabetics, and diabetics based on the questionnaire and diagnostic criteria of the Indian Council of Medical Research (ICMR) guidelines.

Results: In the study, sensitivity and specificity of IDRS score were found to be $84.21 \%$ and $63.4 \%$ respectively for detecting prediabetes in community with the positive predictive value of $51.6 \%$ and negative predictive value of $89.6 \%$ and prevalence of prediabetes in the Chidambaram rural population is $31.6 \%$ among the 60 participants.

Conclusion: The Indian diabetic risk score questionnaire designed by Madras diabetic research federation is a useful screening tool to identify unknown type 2 diabetes mellitus. The questionnaire is a reliable, valuable, and easy to use screening tool which can be used in a primary care setup.

Keywords: IDRS, Prediabetes, FBS, HbA1C, Sensitivity, Specificity, Positive predictive value, Negative predictive value

(C) 2020 The Authors. Published by Innovare Academic Sciences Pvt Ltd. This is an open access article under the CC BY license (http://creativecommons.org/licenses/by/4.0/) DOI: http://dx.doi.org/10.22159/ijpps.2020v12i8.38182. Journal homepage: https://innovareacademics.in/journals/index.php/ijpps.

\section{INTRODUCTION}

Diabetes is one of the leading non-communicable diseases affecting a larger proportion of the population in the world. The global prevalence of type 2 diabetes mellitus in the year 2000 among adults was estimated to be 171 million and will rise to 366 million by 2030 and India is regarded as the diabetic capital of the world with an estimate of 72.9 million diabetic patients $[1,2]$. Hence the identification of persons with the probability of developing diabetes becomes crucial. In this regard, prediabetes as an entity becomes an important factor in identifying high-risk individuals and will go a long way in the prevention and delay of the development of Type 2 diabetes mellitus. The term "Prediabetes" refers to a situation where the blood glucose levels are higher than normal, but not high enough to warrant a diagnosis of diabetes [3]. In this regard, according to the Indian diabetes study report of The Indian Council of Medical Research (ICMR), the vulnerable prediabetic population is estimated to be around 77.2 million currently. Which is more than the current diabetic population in India [4].

Hence, the Prediabetic population has a potential risk of transforming itself into overt diabetes in $5 \mathrm{y}$, if not identified, and interviewed with necessary lifestyle modifications at once [5]. This investigation was embraced to analyse patients in the prediabetic stage and their bunching with the other risk factors for diabetic mellitus. The clustering of risk factors such as overweight and obesity, being older than $40 \mathrm{y}$, sedentary habits, smoking, alcoholism, hypertension, and intake of fruits and vegetables were studied [6]. Early diagnosis and intervention of prediabetic patients and their cluster of risk factor can prevent the cardiovascular events and complications of diabetes such as diabetic retinopathy, neuropathy, and nephropathy [7].

Prediabetics can be identified with several assessment questionnaires; the most common is the IDRS, ADA Questionnaire, CANRISK Questionnaire, AUDRISK Questionnaire, FINRISK Questionnaire [8].
Hence, we aim to identify the vulnerable prediabetic population by way of assessment through the standard Indian Diabetes Risk Score (IDRS). This can be used in identifying pre-diabetic population and prediabetes would be confirmed and verified biochemically (after obtaining informed consent) [9]. Mandatory biochemical protocol as per ICMR guidelines recommendation will be followed, namely, FPG of $110-125 \mathrm{mg} / \mathrm{dl}$ (5.6-6.9 mmol/l), HbA1C of 5.7-6.4 \% (39-46 mmol/l) [10]. The main objective of the study was to assess the performance of the Indian Diabetic Risk Score (IDRS) questionnaire for detecting and predicting risk of type-2 Diabetes Mellitus in a rural Indian population and to identify, assess and prevent the vulnerable prediabetic population becoming diabetic patients in future. We expect considerable outcome for proper prediabetic risk assessment questionnaire for rural Indian set up and also this study group will propose tailor-made lifestyle modification for the identified prediabetics in this study.

\section{MATERIALS AND METHODS}

The study was approved by the Institutional Human Ethics Committee of Annamalai University (Approval No. IHEC/0390/2018) and the date of the approval is 09.01.2019. A cross-sectional descriptive study was carried out among patients attending a master health check-up of RMMCH hospital, Annamalai University located at Chidambaram. The study method involves the selection of participants based on inclusion criteria (non-diabetic patients, subject of both genders and age group between 17 to $60 \mathrm{y}$, participants willing to give consent form and to participate in the study were included) and exclusion criteria (patients who were not willing to participate, known history of DM, pregnant and lactating women). The consent form was obtained from participants who were willing to participate in the study.

Data was recorded on the "Prediabetes risk assessment Questionnaire" and information regarding age, socioeconomic 
status, family history of diabetes and hypertension, physical activity, dietary pattern, weight, height, BMI, waist circumference, and history of smoking and alcohol consumption were recorded. Standard methods were used to measure weight and height and BMI was calculated.

The IDRS was calculated using age, family history of diabetes, physical activity, and waist measurement. Participants were categorized into low $(<30)$, medium (30-59), and high $(>60)$ risk groups based on the IDRS questionnaire. Participants with prediabetes risk were identified by a questionnaire and confirmed with the biochemical investigation. The relevant blood test was taken for identifying prediabetic using Fasting plasma glucose (FBS), Glycated haemoglobin (HbA1C) test. Subjects were classified as normal or prediabetics based on the questionnaire and diagnostic criteria of the Indian Council of Medical Research (ICMR) guidelines.

Table 1: ICMR diagnosis criteria for diabetes and prediabetes [10]

\begin{tabular}{|c|c|c|c|}
\hline Parameters & Normoglycemic & Prediabetes & Diabetes \\
\hline FBS & $<110 \mathrm{mg} / \mathrm{dl}$ & $110-125 \mathrm{mg} / \mathrm{dl}$ & $>126 \mathrm{mg} / \mathrm{dl}$ \\
\hline 2-hrs OGTT & $<140 \mathrm{mg} / \mathrm{dl}$ & $140-199 \mathrm{mg} / \mathrm{dl}$ & $>200 \mathrm{mg} / \mathrm{dl}$ \\
\hline HbA1c & $<5.7 \%$ & $5.7-6.4 \%$ & $>6.5 \%$ \\
\hline
\end{tabular}

The collected information was tabulated, processed and analysed using IBM SPSS statistical tool.

Measures of diagnostic accuracy: sensitivity, specificity, PPV, and NPV

The basic measures of quantification of the diagnostic accuracy of a test include sensitivity and specificity, positive predictive value, and negative predictive value and were calculated using the following equations. The criteria used for assessing True positive, true negative, false positive and False-negative are discussed in foot note of table 6, IDRS VS HBA1C cross-tabulation

$$
\text { Sensitivity }=\frac{\text { True Positive }}{\text { True Positive }+ \text { False Negative }} \times 100
$$

The sensitivity of a diagnostic test quantifies its ability to correctly identify subjects with the disease condition. It is the proportion of true positives that are correctly identified by the test.

$$
\text { Specificity }=\frac{\text { True Negative }}{\text { True Negative }+ \text { False positive }} \times 100
$$

The specificity is the ability of a test to correctly identify subjects without the condition. It is the proportion of true negatives that are correctly identified by the test

$$
\text { Positive Predictive Value }=\frac{\text { True Positive }}{\text { True Positive }+ \text { False Positive }} \times 100
$$

Positive predictive value shows the probability of a person with a disease or condition when the test is positive.

$$
\text { Negative Predictive Value }=\frac{\text { True Negative }}{\text { True Negative }+ \text { False Negative }} \times 100
$$

Negative predictive value shows the probability of a person with not developing disease or condition when the test is negative [11-13].

\section{RESULTS}

\begin{tabular}{|c|c|c|}
\hline Age & No of participants $(\mathrm{N}=60)$ & Percentage (\%) \\
\hline$<35$ & 18 & $30 \%$ \\
\hline $35-49$ & 19 & $31 \%$ \\
\hline$>50$ & 23 & $38 \%$ \\
\hline Total & 60 & $100 \%$ \\
\hline
\end{tabular}

A total of 60 participants were enrolled in the study. The subjects were divided into three age groups, viz, $<35 ; 35$ to $49 ;>50 \mathrm{y}$.

Table 2: Age-wise distribution of study participants $(\mathrm{N}=60)$

The age wise-distribution of the study had shown that the maximum number of participants (23 participants, 38\%) belongs to the age group of $>50$ $\mathrm{y}$, among the total of 60 participants. However, there was a gradual increase in the enrolment of patients as the age increases, but the change is not significant.

Table 3: Distribution of subjects in categories of BMI classification $(\mathrm{N}=60)$

\begin{tabular}{lll}
\hline BMI $\left(\mathbf{k g} / \mathbf{m}^{\mathbf{2}}\right)$ & No of participants $\mathbf{( N = 6 0 )}$ & Percentage \\
\hline Underweight $(<19)$ & 2 & $3 \%$ \\
Normal $(20-24.9)$ & 14 & $23 \%$ \\
Overweight $(25-29.9)$ & 25 & $41 \%$ \\
Obese $(>30)$ & 19 & $31 \%$ \\
Total & 60 & $100 \%$ \\
\hline
\end{tabular}

The subjects were classified in to different categories of BMI, based on the revised consensus guidelines for Asian Indians. In the study population, $41 \%$ were considered overweight, $31 \%$ were considered obese, $3 \%$ were considered underweight, and $23 \%$ were having normal BMI. Since BMI is one of the predisposing factor for the development of diabetes, around $(41+31=72 \%)$ of patients have a risk to develop diabetes in the future.

In the present study out of 60 subjects, 31(52\%) come under high risk, 22 (37\%) come under moderate risk, 7 (11.6\%) come under low risk as per the IDRS risk score. The study shows that the majority $(52 \%)$ of subjects come under high-risk category and this is an alarming signal as this $52 \%$ of patients have a greater probability to develop diabetes within a span of 5 to $10 \mathrm{y}$.

The values of FBS and HbA1c were comparable in case of prediabetic category $(33 \%, 32 \%)$, whereas in case of hyperglycaemic, FBS and HbA1C were showing lower percentages $(0,3.3 \%)$ diabetes.

According to biochemical investigations (FBS and $\mathrm{HbA} 1 \mathrm{C}$ ), percentages of participants having a prediabetic risk factor were $33 \%$ and $32 \%$ respectively and were comparable. However, according to IDRS Score, $52 \%$ of patients belong to the high-risk category; this provides a strong signal that they may develop 
diabetes in the future. IDRS score comprises various parameters like waist circumference (physiology), physical activity (lifestyle), and family history (genetic predisposition) and it is a more relevant measure and to predict the probability of developing diabetes in the future.

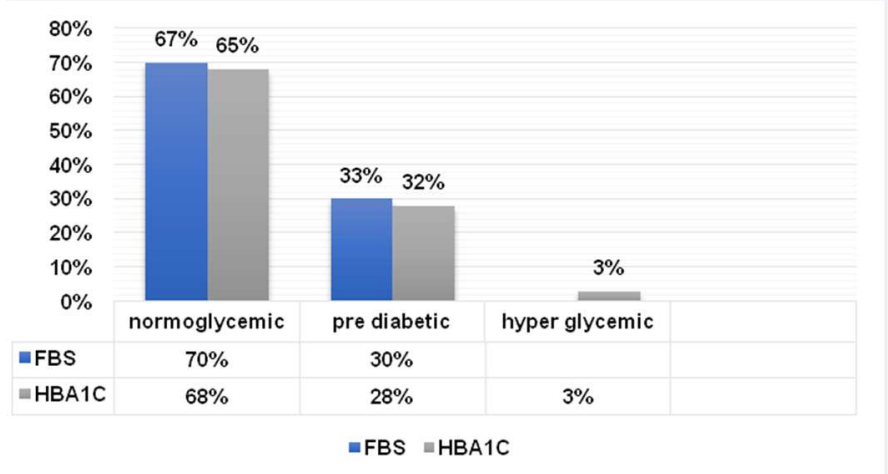

Fig. 1: Comparison of normoglycemic, prediabetic and diabetic population-based on FBS and HbA1c result

Table 4: Distribution of study subjects according to demography details and risk as per IDRS $(\mathrm{N}=60)$

\begin{tabular}{|c|c|c|c|c|c|c|c|c|c|}
\hline \multirow[t]{3}{*}{ Variables } & & \multicolumn{6}{|c|}{ IDRS Risk } & \multirow{2}{*}{\multicolumn{2}{|c|}{ Total }} \\
\hline & & \multicolumn{2}{|c|}{ Low } & \multicolumn{2}{|c|}{ Moderate } & \multicolumn{2}{|c|}{ High } & & \\
\hline & & No & $\%$ & No & $\%$ & No & $\%$ & No. & $\%$ \\
\hline \multirow[t]{2}{*}{ Gender } & Male & 7 & $11.6 \%$ & 14 & $23.3 \%$ & 17 & $28.3 \%$ & 38 & $63.3 \%$ \\
\hline & Female & 0 & $0 \%$ & 9 & $15 \%$ & 13 & $21.6 \%$ & 22 & $36.6 \%$ \\
\hline \multirow[t]{3}{*}{ Age } & $<35$ & 6 & $10 \%$ & 9 & $15 \%$ & 1 & $1.6 \%$ & 16 & $26.6 \%$ \\
\hline & $35-45$ & 1 & $1.6 \%$ & 9 & $15 \%$ & 10 & $16.6 \%$ & 20 & $33.3 \%$ \\
\hline & $>50$ & 0 & $0 \%$ & 5 & $8.3 \%$ & 19 & $31.6 \%$ & 24 & $40 \%$ \\
\hline \multirow[t]{2}{*}{ Food Habits } & Vegetarian & 2 & $3.3 \%$ & 1 & $1.7 \%$ & 4 & $6.7 \%$ & 7 & $11.6 \%$ \\
\hline & Non-Vegetarian & 5 & $8.3 \%$ & 22 & $36.7 \%$ & 26 & $43.3 \%$ & 53 & $88.3 \%$ \\
\hline \multirow[t]{2}{*}{ Alcoholic } & Yes & 2 & $3.3 \%$ & 9 & $15 \%$ & 8 & $13.3 \%$ & 19 & $31.6 \%$ \\
\hline & No & 5 & $8.3 \%$ & 14 & $23.3 \%$ & 22 & $36.7 \%$ & 41 & $68.4 \%$ \\
\hline
\end{tabular}

Among 38 male participants, $(17 / 38 \times 100=44.7 \%)$ were in IDR high-risk category whereas among 22 female participants, $(13 / 22 \times 100=59.1 \%)$ were in IDRS high-risk category. The reason for the higher $\%$ in females may be due to lesser physical activity, hormonal imbalances, and sedentary lifestyle.

Among 24 participants in the age group of ( $>50$ y), 19 participants $(19 / 24 \times 100=79.1 \%)$ were having a high-risk IDRS score.

Regarding food habit, among 7 vegetarians, 4 participants $(4 / 7 \times 100=57.1 \%)$ of participants belong to high-risk IDR score highrisk, and among 53 non-vegetarians, 26 participants $(26 / 53 \times 100=$ $49 \%$ ) of participants belong to high-risk IDR score.
On analysing the association between alcoholic and IDRS in our study, among 19 alcoholics, 8 participants $(8 / 19 \times 100=42.1 \%)$ belong to high-risk IDR score and among 41 non-alcoholics, 22 participants $(22 / 41 \times 100=53.6 \%)$ belongs to high-risk IDR score. Since we are measuring parameters mostly from healthy people, the majority of participants were occasional drinkers.

Body Mass Index (BMI) is considered to be one of the contributing risk factors for prediabetes. Among 25 participants in BMI overweight category, 13 participants $(13 / 25 \times 100=52 \%)$ belong to the high-risk category, and among 15 participants in BMI obese category, 11 participants $(11 / 15 \times 100=73.3 \%)$ belong to high-risk category. Hence as BMI increases, the chance of getting prediabetes also increases.

Table 5: Distribution of study subjects according to BMI details and risk as per IDRS

\begin{tabular}{|c|c|c|c|c|c|c|c|c|}
\hline \multicolumn{9}{|c|}{ BMI * IDRS cross-tabulation } \\
\hline \multicolumn{9}{|c|}{ Count } \\
\hline \multirow{2}{*}{\multicolumn{2}{|c|}{ Categories }} & \multicolumn{6}{|c|}{ IDRS } & \multirow[t]{2}{*}{ Total } \\
\hline & & & & Mo & & Hig & & \\
\hline \multirow{4}{*}{ BMI } & Below Weight & 2 & $50 \%$ & 2 & $50 \%$ & 0 & $0 \%$ & 4 \\
\hline & Normal Weight & 3 & $18.7 \%$ & 7 & $43.7 \%$ & 6 & $37.1 \%$ & 16 \\
\hline & Over Weight & 1 & $4 \%$ & 11 & $44 \%$ & 13 & $52 \%$ & 25 \\
\hline & Obese & 1 & $6.6 \%$ & 3 & $20 \%$ & 11 & $73.3 \%$ & 15 \\
\hline \multicolumn{2}{|c|}{ Total } & 7 & $11.6 \%$ & 23 & $38.3 \%$ & 30 & $5 \mathrm{~S} 0 \%$ & 60 \\
\hline
\end{tabular}

Table 6: IDRS VS HBA1C cross-tabulation

\begin{tabular}{lllll}
\hline IDRS VS HBA1C cross-tabulation & & & \\
\hline Count & & HBA1C & Total \\
\cline { 3 - 4 } & & Positive & Negative & 31 \\
\hline IDRS & Positive & 16 & 15 & 29 \\
& Negative & 3 & 26 & 60 \\
Total & & 19 & 41 & 60 \\
\hline
\end{tabular}

True positive $\square$, False negative $\square$, False positive $\square$, True negative $\square$ 
$>$ True Positive value indicates no. of participants who were positive both in the IDRS score (having scores more than 60) and HbA1C values (having $\mathrm{HbA1C}$ value between 5.7 to $6.4 \%$ ). In our study, true positive value equals 16

$>$ True negative value indicates no. of participants who were negative both in the IDRS score (having scores less than 60) and $\mathrm{HbA1C}$ values (having HbA1C value less than 5.7 as well as $\geq 6.5 \%$ ). In our study, true negative value equals 26 .

$>$ False-negative value indicates no. of participants who were negative in IDRS score (having scores less than 60) and positive in the $\mathrm{HbA} 1 \mathrm{C}$ values (having $\mathrm{HbA} 1 \mathrm{C}$ value between 5.7 to $6.4 \%$ ). In our study, false-negative value equals 3 .

$>$ False Positive value indicates no. of participants who were positive in IDRS score (having scores more than 60) and negative in the $\mathrm{HbA1C}$ values (having $\mathrm{HbA1C}$ value less than 5.7 as well as $\geq$ $6.5 \%$ ). In our study, false-negative value equals 15 .

Therefore:

$$
\begin{aligned}
\text { 1. Prevalence }= & \frac{\text { True Positive }+ \text { False Negative }}{\text { Total Population }} \times 100 \\
& =(16+3) / 60 \times 100
\end{aligned}
$$

Prevalence $=31.6 \%$

$$
\begin{aligned}
\text { 2. Sensitivity }= & \frac{\text { True Positive }}{\text { True Positive }+ \text { False Negative }} \times 100 \\
& =16 /(16+3) \times 100
\end{aligned}
$$

Sensitivity $=84.21 \%$

$$
\begin{aligned}
3 . \text { Specificity }= & \frac{\text { True Negative }}{\text { True Negative }+ \text { False positive }} \times 100 \\
& =26 /(26+15) \times 100
\end{aligned}
$$

Specificity $=63.4 \%$

$$
\begin{aligned}
& \text { 4. Positive Predictive Value }=\frac{\text { True Positive }}{\text { True Positive }+ \text { False Positive }} \times 100 \\
& =16 /(16+15) \times 100
\end{aligned}
$$

Positive predictive value $=51.6 \%$

5. Negative Predictive Value

$$
\begin{aligned}
& =\frac{\text { True Negative }}{\text { True Negative }+ \text { False Negative }} \times 100 \\
& =26 /(26+3) \times 100
\end{aligned}
$$

Negative predictive value $=89.6 \%$

Based on the calculations, the prevalence for prediabetes was around $31.6 \%$ among 60 participants drawn from the rural population. The sensitivity and specificity of the IDRS score were found to be $84.21 \%$ and $63.4 \%$, respectively. Positive predictive values were found to be $51.6 \%$ and negative predictive values were found to be $89.6 \%$. Positive predictive value $51.6 \%$ shows that the probability of a person with prediabetes when the IDRS score is positive (having scores more than 60 ). Negative predictive value $89.6 \%$ shows the probability of a person not developing prediabetes when the IDRS score is negative (having score less than 60).

In our study, the sensitivity of $84.21 \%$, a specificity of $63.4 \%$ was observed for determining undiagnosed diabetes in the community with a positive predictive value of $51.6 \%$ and a negative predictive value of $89.6 \%$.

\section{DISCUSSION}

There are many Diabetic risk assessment questionnaires and tools developed by various National and International diabetic associations all over the world, and they have variations in assessment based on the ethnic group, lifestyle, and races. The most commonly used Questionnaires are ADA Questionnaire, CANRISK Questionnaire, AUDRISK Questionnaire, and Indian Diabetic Risk
Score (IDRS). IDRS developed by Chennai Urban Rural Epidemiology Study (CURES) and Madras Diabetic Research Foundation (MDRF) is found to be the most suitable, simple, and easy tool to identify undiagnosed diabetes in our country [9]. The IDRS is calculated using four risk factors: age, family history of diabetes, physical activity, and waist circumference measurement. This is of great significance as the use of such a scoring system could prove to be a cost-effective tool for screening of diabetes. Further, the use of such a risk score would be of great help in developing countries like India where there is a marked explosion of diabetes, and over half of the cases remain undiagnosed diabetes [14]. Measurement of waist circumference as a measure of abdominal obesity plays a significant role in the identification of the development of type 2 diabetes mellitus. In the Indian population lean body mass index also is considered as one of the factors for the development of Type 2 diabetes mellitus. Hence, instead of BMI, the measurement of waist circumference makes a better screening tool for assessing type 2 diabetes mellitus and its risk in the Indian population $[15,16]$.

From the results of our study using Indian diabetic risk score, a higher degree of sensitivity $84.21 \%$ and specificity of $63.4 \%$ were observed for determining undiagnosed diabetes in the community with a positive predictive value of $51.6 \%$ and negative predictive value of $89.6 \%$. This value is comparable with the value of IDRS developed by Mohan et al. (2005). CURES study has revealed sensitivity (72.5\%) and specificity (60.1\%) for determining undiagnosed diabetes in the community with a positive predictive value of $17.0 \%$, the negative predictive value of $95.1 \%$ when the IDRS Score $>60$ [17]. Similarly, Stanley et al. validate IDRS in the South Indian population, and study results show sensitivity and specificity of $100 \%$ and $17 \%$. Puja Dudeja et al. has used IDRS and predicted the risk of diabetes with a sensitivity of $95.12 \%$ and $28.95 \%$ when the sore $>60[18,19]$. Ramachandran et al. also developed a Diabetes Risk Assessment Score for the south India population, which was validated in three cohorts. They have included BMI also for the assessment of the risk of type 2 diabetic Mellitus with a score of $>21$ gave a sensitivity, specificity, positive predictive value, and negative predictive value of $76.6 \%, 59.9 \%$, $9.4 \%$, and $97.9 \%$ [20]. The prevalence of prediabetes in the current study was $31.6 \%$. The higher prevalence of prediabetic in a rural Tamil Nadu population may be due to a lack of awareness about a healthy diet and lack of physical activity. Beagley et al. in the global estimation study reported a prevalence of prediabetic and diabetes in adults to vary between $24.1 \%$ and $75.1 \%$ respectively [21]. Dasappa et al. had reported a prevalence of diabetic and prediabetic in the urban slum of Bangalore as $12.33 \%$ and $11.57 \%$ respectively [22]. Ravikumar et al. has carried out a study in the urban locality of Chandīgarh and reported a low prevalence $(6.3 \%)$ of prediabetics. Thus prediabetic population has a potential risk of transforming itself into overt diabetes in $5 \mathrm{y}$, if not identified and interviewed with necessary lifestyle modification at once [23]. The current study shows that diabetes is one of the major risk factors for developing cardiovascular events and death [24]. Therefore, early diagnosis and intervention of prediabetics and their cluster of a risk factor can prevent the cardiovascular events and complications of diabetes such as diabetic retinopathy, neuropathy, and nephropathy.

In developing countries like India, half of the newly diagnosed patients were identified only at a later stage due to a lack of awareness and knowledge about diabetes. IDRS is user friendly, simple, fast, economical, and effective screening tool to identify prediabetes at an earlier stage, prior to the actual confirmation of diabetes using blood level investigation. This will help to reduce the screening cost of diabetes by nearly half. IDRS also help to identify a person at risk of having prediabetes in our population. Moreover, IDRS will help to create awareness and motivate people, who have a higher risk of developing diabetes in the future and to monitor blood glucose levels frequently as a precautionary measure to predict diabetes.

\section{LIMITATION OF THE STUDY}

Initially, 150 participants were enrolled in the study from the Department of medicine, RMMCH, Chidambaram. But some of them were not willing to take the $\mathrm{HbA1c}$ test as it involves invasive 
procedures and is quite expensive. Since it is a self-funding project, we could not take the HbA1c test for a few participants.

\section{CONCLUSION}

In this study, we have assessed the performance of Indian diabetic risk score (IDRS) in a rural population setup of Chidambaram From the study we conclude that IDRS is found to be a simple, fast, noninvasive and fairly accurate tool for screening of undiagnosed Type 2 diabetes which can be used in a primary health care facility. According to our study, the prevalence of prediabetes in the rural population is $31.6 \%$ with a sensitivity of $84.21 \%$ and specificity of $63.4 \%$ when the IDRS score was more or equal to 60 , with a positive predictive value of $51.6 \%$ and negative predictive value of $89.6 \%$. Since India is considered as the diabetic capital of the world with an estimate of 70 million diabetic patients and still a higher estimate of around 77 million identified as prediabetes, our study can make a significant contribution in decreasing the burden of diabetes in the near future.

\section{ACKNOWLEDGMENT}

We extend our humble gratitude to Dr. G. P. Mohanta, professor and Head, and to Dr. P. K. Manna Former Professor and Head, Department of Pharmacy, Dr. C. K. Dhanapal, Professor of Pharmacy and Pharm. D Coordinator, Dr. V. U. Shanmugam, Medical Superintendent, Dr. S. Selvamuthukumaran, Former Assistant Medical Superintendent, RMMCH and Associate Professor of Medicine and Dr. S. Balasubramaniyan, Professor and Head, Department of Medicine for their help, support and suggestions in the execution of our Pharm. D. project.

\section{FUNDING}

Nil

\section{AUTHORS CONTRIBUTIONS}

All listed authors have contributed equally to the design and perform of the research to the analysis of the results and to the writing of the manuscript.

\section{CONFLICT OF INTERESTS}

The authors declare that there are no conflicts of interests.

\section{REFERENCES}

1. Sangam K, Anifa M, K S, K V, Reddy TRM. Evaluation of pharmacoeconomic direct cost in diabetes patients. Asian J Pharm Clin Res 2017;10:38-40.

2. Anjana R, Pradeepa R, Deepa M, Datta M, Sudha V, Unnikrishnan R, et al. Prevalence of diabetes and prediabetes (impaired fasting glucose and/or impaired glucose tolerance) in urban and rural India: phase I results of the Indian council of medical research-India diabetes (ICMR-INDIAB) study. Diabetologia 2011;54:3022-7.

3. Matthew C Riddle. Classification and diagnosis of diabetes: standards of medical care in diabetes-2019. Diabetes Care 2019;42 Suppl 1:S13-S28.

4. Kandasamy K, Rajagopal SS, Ramalingam K, Krishnan K. Prevalence of diagnosed and undiagnosed diabetes in a rural community: a home-based screening. Asian J Pharm Clin Res 2018;11:454-7.

5. Phillip Tuso. Prediabetes and lifestyle modification: time to prevent a preventable disease. Perm J 2014;18:88-93.

6. Goldenberg R, Punthakee Z. Definition, classification and diagnosis of diabetes, prediabetes and metabolic syndrome. Can J Diabetes 2013;37:S8-S11.
7. Muthunarayanan L, Ramraj B, Russel J. Prevalence of prediabetes and its associated risk factors among rural adults in Tamil Nadu. Arch Med Health 2015;3:178-84.

8. Stiglic G, Pajnkihar M. Evaluation of major online diabetes risk calculators and computerized predictive models. PLOS One 2015;10:e0142827.

9. Madhavi P, KVP. Screening for undiagnosed diabetic subjects using a simplified Indian diabetes risk score [IDRS] in Khammam urban. J Evidence Based Med Healthcare 2016;3:2876-9.

10. ICMR Guidelines for management of type 2 diabetes 2018 . India: ICMR; 2018. p. 9-10.

11. Wong H, Lim G. Measures of diagnostic accuracy: sensitivity, specificity, ppv and npv. Proceedings Singapore Healthcare 2011;20:316-8.

12. Altman D, Bland J. Statistics notes: diagnostic tests 1 : sensitivity and specificity. Br Med J 1994;308:1552.

13. Parikh R, Mathai A, Parikh S, Chandra Sekhar G, Thomas R. Understanding and using sensitivity, specificity and predictive values. Indian J Ophthalmol 2008;56:45-50.

14. Mohan V, Deepa R, Deepa M, Somannavar S, Datta M. A simplified Indian diabetes risk score for screening for undiagnosed diabetic subjects. J Assoc Physicians India 2005;53:759-63.

15. Adhikari P, Pathak R, Kotian S. Validation of the MDRF-Indian diabetes risk score (IDRS) in another south Indian population through the boloor diabetes study (BDS). J Assoc Physicians India 2010;58:434-6.

16. Sheikh Mohd Saleem, Adnan Firdous Raina, S Muhammad Salim Khan, Shah Sumaya Jan. Indian diabetic risk score-A tool for predicting risk of undiagnosed type 2 diabetes mellitus. Int J Curr Res Rev 2017;9:39-42.

17. Khan M, Sonkar G, Singh S, Sonkar S. Importance of the madras diabetes research foundation-Indian diabetes risk score (MDRF-IDRS) for mass screening of type 2 diabetes and its complications at primary health care centers of North India. Int J Diabetes Dev Countries 2019;39:419-25.

18. Stanley JM, Elantamilan D, Mohanasundaram K, Kumaravel TS Evaluation of Indian diabetic risk score for screening undiagnosed diabetes subjects in the community. Indian J Sci Technol 2012;5:2798-9.

19. Dudeja P, Singh G, Gadekar T, Mukherji S. Performance of Indian diabetes risk score (IDRS) as a screening tool for diabetes in an urban slum. Med J Armed Forces India 2017;73:123-8.

20. Ramachandran A, Snehalatha C, Vijay V, Wareham NJ, Colagiuri S. Derivation and validation of diabetes risk score for Urban Asian. Diabetes Res Clin Practice 2005;70:63-70.

21. Beagley J, Guariguata L, Weil C, Motala AA. Global estimates of undiagnosed diabetes in adults. Diabetes Res Clin Pract 2014;103:150-60.

22. Dasappa H, Fathima FN, Prabhakar R, Sarin S. Prevalence of diabetes and prediabetes and assessments of their risk factors in urban slums of Bangalore. J Family Med Primary Care 2015;4:399-404.

23. Ravikumar P, Bhansali A, Ravikiran M. Prevalence and risk factors of diabetes in a community-based study in North India: the Chandigarh urban diabetes study (CUDS). Diabetes Metab 2011;37:216-21.

24. Narayan KM, Gregg EW, Fagot Campagna A, Engelgau MM, Vinicor F. Diabetes--a common, growing, serious, costly, and potentially preventable public health problem. Diabetes Res Clin Pract 2000;50 Suppl 2:S77-S84. 